\title{
Op pad na 'n omvattende woordeboekkultuur in die digitale era
}

Rufus H. Gouws, Departement Afrikaans en Nederlands, Universiteit Stellenbosch, Stellenbosch, Suid-Afrika(rhg@sun.ac.za)

\begin{abstract}
Towards a Comprehensive Dictionary Culture in the Digital Era. Following a brief introduction this paper offers a discussion of certain aspects of the development of theoretical lexicography. Specific attention is drawn to among others different phases in this development, provision that has to be made for the use of different lexicographic tools and also the user-perspective. The main focus of this contribution is on the development of a comprehensive dictionary culture that unites the traditional division between user-friendliness and dictionary culture in one encompassing comprehensive dictionary culture. A bidirectional relation between society and lexicography is discussed and it is indicated that certain adaptations need to be made in order to improve the comprehensive dictionary culture. This includes both lexicographic and extra-lexicographic adaptations. The distinction between a collective and an individual comprehensive dictionary culture is discussed and it is suggested that dictionary culture should not be a separate main component of dictionary research but should rather be integrated into all four existing main components. Many potential dictionary users within the digital era belong to Generation $Z$. Some features of this generation are briefly discussed. The need is indicated for an adaptation in lexicography that could motivate this generation to use dictionaries. It is argued that dictionary didactics should play an important role in establishing a comprehensive dictionary culture within Generation Z. This dictionary culture should also be directed at other reference sources.
\end{abstract}

Keywords: COMPREHENSIVE DICTIONARY CULTURE, DICTIONARY CULTURE, DICTIONARY DIDACTICS, DICTIONARY RESEARCH, DIGITAL ERA, EXTRA-LEXICOGRAPHIC ASPECTS, GENERATION Z, LEXICOGRAPHIC TOOLS, METALEXICOGRAPHY, ONLINE DICTIONARIES, TYPES OF USERS, USER-FRIENDLINESS

Opsomming: Na 'n kort inleiding bied dié artikel 'n bespreking van bepaalde aspekte van die ontwikkeling van die leksikografieteorie. Spesifieke aandag word gegee aan onder meer verskillende fases in dié ontwikkeling, voorsiening wat gemaak moet word vir die gebruik van verskillende leksikografiese werktuie, asook die gebruikersperspektief. Die hooffokus van hierdie artikel is op die ontwikkeling van 'n omvattende woordeboekkultuur wat die tradisionele verdeling tussen gebruikersvriendelikheid en woordeboekkultuur onder een oorkoepelende omvattende woordeboekkultuur verenig. ' $n$ Tweerigtingverhouding tussen samelewing en leksikografie word bespreek en daar word gewys op bepaalde aanpassings wat gemaak moet word ter verbetering van die woordeboekkultuur. Dit sluit sowel leksikografiese as buiteleksikografiese aanpassings in. Die onderskeid tussen 'n kollektiewe en 'n indiwiduele omvattende woordeboekkultuur word bespreek 
en daar word voorgestel dat woordeboekkultuur nie ' $n$ afsonderlike hoofkomponent van woordeboeknavorsing moet wees nie, maar eerder in al vier die bestaande hoofkomponente geïntegreer moet word. In die digitale era behoort baie potensiële woordeboekgebruikers tot Generasie Z. Kenmerke van hierdie gebruikersgroep word kortliks bespreek. Die behoefte aan 'n aanpassing in die leksikografie om lede van Generasie Z by woordeboekgebruik te betrek, word genoem. Daar word van die standpunt uitgegaan dat woordeboekdidaktiek 'n belangrike rol moet speel in die vestiging van 'n omvattende woordeboekkultuur onder hierdie geslag gebruikers. Dié woordeboekkultuur moet ook op die gebruik van ander naslaanbronne gerig wees.

Sleutelwoorde: AANLYN WOORDEBOEKE, BUITELEKSIKOGRAFIESE ASPEKTE, DIGITALE ERA, GEBRUIKERSTIPES, GEBRUIKERSVRIENDELIKHEID, GENERASIE Z, LEKSIKOGRAFIESE WERKTUIE, METALEKSIKOGRAFIE, OMVATTENDE WOORDEBOEKKULTUUR, WOORDEBOEKDIDAKTIEK, WOORDEBOEKKULTUUR, WOORDEBOEKNAVORSING

\section{Inleiding}

In die lang geskiedenis van die leksikografiese praktyk is daar blyke van ' $n$ verskeidenheid aanpassings wat gelei het tot die huidige stand van woordeboeke as praktiese gebruiksinstrumente, vergelyk onder meer McArthur (1986) en Gouws, Schweickard en Wiegand (2013). Van die ingrypende aanpassings wat die ontwikkeling van die leksikografie kenmerk, was die oorgang van woordeboeke op kleitablette en papirusblare na woordeboeke op perkament en later papier, die oorgang vanaf woordeboeke met ' $n$ tematiese ordening na woordeboeke met ' $n$ alfabetiese ordening, die vestiging van 'n preskriptiewe benadering en die geleidelike oorgang vanaf 'n preskriptiewe na 'n deskriptiewe benadering, die oorgang vanaf 'n kaartversameling na 'n elektroniese korpus en, meer onlangs, die oorgang vanaf gedrukte na aanlyn woordeboeke. 'n Groter blootstelling aan en gebruik van woordeboeke het ook 'n oorgang vanaf ' $n$ prewoordeboekkultuurera na 'n era gekenmerk deur 'n meer gevestigde woordeboekkultuur meegebring.

Hierdie aanpassings het tot eiesoortige vernuwing in die leksikografie gelei - vernuwing ten opsigte van medium, ten opsigte van inhoud en werkswyse en in sommige gevalle ook ten opsigte van die geldende teoretiese benadering. In die aktiewe wisselwerking tussen leksikografieteorie en die leksikografiepraktyk is dit insiggewend om te let op die rol wat die teoretiese leksikografie in hierdie oorgange gespeel of nie gespeel het nie. Met die praktyk wat veel ouer as die teorie is, was daar talle aanpassings wat uitsluitlik op die praktyk gerig en deur praktiese behoeftes bepaal is, soos onder meer die oorgang na perkament en papier en die benutting van die alfabetiese ordening. In ander gevalle het die leksikografieteorie, of minstens bepaalde vroeë teoretiese insigte, wel 'n rol gespeel. ' $n$ Voorbeeld hiervan was die vestiging van ' $n$ preskriptiewe benadering in Samuel Johnson se A Dictionary of the English Language (1755). Die werkswyse wat hy gevolg het en die vaslegging van sy bena- 
dering van "fixing the language" is voorafgegaan deur die dokument wat hy in 1747 gepubliseer het, te wete sy bekende The Plan of a Dictionary of the English Language - 'n vroeë voorbeeld van 'n teoretiese uiteensetting wat in die praktyk toegepas kon word.

In onlangse jare, lank na die vestiging van die teoretiese leksikografie, is die oorgang na aanlyn woordeboeke vergesel van pogings om die heersende leksikografieteorie wat veral op gedrukte woordeboeke gerig was, uit te brei en aan te pas om ook as teoretiese basis vir aanlyn woordeboeke te dien. Die oorgang na die aanlyn leksikografie het 'n ingrypende invloed op die ontwikkeling in die teoretiese leksikografie gehad, aangesien die nuwe medium nuwe moontlikhede bied maar ook andersoortige eise stel wat nie sonder meer deur die algemene leksikografieteorie in sy gerigtheid op gedrukte woordeboeke bevredig kan word nie. Daar moes besluit word of daar 'n nuwe teorie vir aanlyn woordeboeke ontwerp moet word en of die bestaande teorie aangepas en uitgebrei moet word om vir sowel gedrukte as aanlyn woordeboeke voorsiening te maak. Die laasgenoemde keuse impliseer dat sommige aspekte van die teorie net op gedrukte, ander op gedrukte en aanlyn en ander slegs op aanlyn woordeboeke van toepassing sal wees. So 'n algemene teorie sal sterker wees as twee afsonderlike teorieë. Dit is die uitgangspunt wat in hierdie artikel gehandhaaf word.

Omdat die praktiese leksikografie veel ouer as die teoretiese leksikografie is, het die teorie baie lank ' $n$ navolgersrol gespeel wat 'n beskrywing moes bied van dit wat reeds in die praktyk plaasgevind het. Algaande het die teorie ingehaal en mettertyd ook 'n leiersrol begin speel deurdat voorstelle gemaak kon word vir vernuwende werk in die leksikografiese praktyk.

Die koms van die digitale era het 'n soortgelyke verhouding tussen praktyk en teorie in die leksikografie tot gevolg gehad as wat vroeër die geval in die ontwikkeling van gedrukte woordeboeke was. Aanlyn woordeboeke wat ontwikkel is, het dikwels nie genoegsaam blyke gegee van 'n metaleksikografiese grondslag nie. Een van die redes hiervoor is daarin geleë dat metaleksikograwe nie voldoende aandag gegee het aan die aanpassings wat in die leksikografieteorie gemaak moes word nie. Ook hier het daar mettertyd 'n verandering ingetree wat weer eens algaande die navolgersrol van die metaleksikografie tot ' $n$ leiersrol omskep het. Die leksikografieteorie maak naamlik toenemend voorsiening vir ' $n$ algemener benadering wat nie mediumspesifiek is nie en wat ook as basis vir die beplanning en samestelling van aanlyn woordeboeke kan dien.

Die oorgang na die aanlyn leksikografie is die gevolg van die koms van die digitale era. Dit is ' $n$ omvattende oorgang in eie reg; nie net in die leksikografie nie. In die leksikografie het dit tot baie aanpassings gelei wat nie hier uitvoerig bespreek word nie. Een groot aanpassing wat nog nie gemaak is nie, maar waarvoor daar in hierdie artikel gepleit word, is die aanpassing in die interpretasie van die begrip woordeboekkultuur en die implikasies daarvan vir onder meer woordeboekdidaktiek en die gevolglike ontwikkeling van sowel die teoretiese as die praktiese leksikografie. Dit staan sentraal in hierdie artikel. 


\section{Ontwikkeling in die leksikografieteorie}

\subsection{Teorie en praktyk}

Leksikografie val in 'n teoretiese en 'n praktiese komponent uiteen. Die leksikografiese praktyk was eerste daar en ouer woordeboeke het in 'n preteoretiese era tot stand gekom. Met die koms van die leksikografieteorie, veral in die laaste drie dekades van die vorige eeu, moes metaleksikograwe eerstens terugskouend werk om 'n teoretiese beskrywing te bied van dit wat reeds in die praktyk beslag gekry het. Mettertyd is die nodige inhaalwerk gedoen en kon teoretici ook vorentoe kyk en vernuwende modelle ontwikkel wat leiding aan praktiserende leksikograwe gebied het vir die beplanning en ontwerp van leksikografiese produkte. Die kontemplatiewe benadering van vroeë metaleksikograwe is ondersteun deur 'n transformatiewe benadering, vergelyk Tarp (2008: 10) vir ' $n$ bespreking van hierdie begrippe.

Die koms van die digitale era het al gou tot die daarstelling van 'n verskeidenheid e-woordeboeke aanleiding gegee. Die eerste woordeboeke wat in die digitale medium saamgestel is, was woordeboeke op CD-ROM. Hierdie woordeboeke was in die meeste gevalle slegs digitale weergawes van bestaande gedrukte woordeboeke. Daar was weliswaar 'n bepaalde toegevoegde waarde, onder meer die vinniger toegangsmoontlikhede, maar die aard en omvang van die woordeboekinhoud en die aanbieding daarvan het nie veel verskil van dié van hierdie woordeboeke se gedrukte teenhangers nie. Wat wel opmerklik was in hierdie fase van die oorgang van gedrukte na e-woordeboeke was die gebrek aan teoretiese bydraes met voorstelle oor hoe hierdie e-woordeboeke ten beste beplan en saamgestel kon word. Die praktyk het weer eens die voortou geneem met uitgewers wat bestaande gedrukte woordeboeke in CD-ROM-formaat beskikbaar gestel het sonder dat metaleksikograwe genoegsaam geraadpleeg is of hoegenaamd leiding gegee het oor nuwe teoretiese modelle wat in die praktyk toegepas kon word.

'n Volgende fase in die ontwikkeling van e-woordeboeke was die toetrede van aanlyn woordeboeke en dit was die aanbreek van die werklike oorgang vanaf gedrukte na digitale woordeboeke. Sommige aanlyn woordeboeke is steeds nie veel meer as digitale weergawes van gedrukte woordeboeke nie. Die vernuwende aanlyn woordeboeke is daardie produkte wat nie 'n gedrukte teenhanger het nie en wat van meet af as aanlyn produk beplan en saamgestel is. Ook hier is die verhouding tussen teorie en praktyk ter sake. Die tegnologie om digitale woordeboeke te maak, het vinniger ontwikkel as die pogings van metaleksikograwe om die leksikografieteorie so aan te pas dat dit genoegsaam vir produkte in die nuwe medium voorsiening gemaak het. Weer eens het die teorie ' $n$ navolger van die praktyk geword en nie 'n leier nie.

\subsection{Fases in die ontwikkeling van die leksikografieteorie}

In die ontwikkeling van die algemene leksikografieteorie was daar verskillende 
fases met verskillende fokusgebiede, te wete ' $n$ fokus op woordeboekinhoud, op woordeboekstrukture en op woordeboekfunksies, vergelyk Gouws (2005). Die formulering van leksikografiese funksies, vgl. Tarp (2008), is op so 'n wyse gedoen dat dit nie mediumspesifiek is nie. Hierdie teoretiese benadering geld gevolglik én vir gedrukte én vir aanlyn woordeboeke. Woordeboekinhoud word grootliks deur die behoeftes van die teikengebruiker bepaal. Aanlyn woordeboeke bied in talle gevalle dieselfde inhoud as gedrukte woordeboeke. Die groot verskil lê in die aanbieding van data wat dit in aanlyn woordeboeke makliker maak vir gebruikers om die verlangde inligting te kan onttrek. Een van dié wesenlike aanpassings wat in die leksikografieteorie gemaak moet word om ook vir aanlyn woordeboeke voorsiening te maak, is op die vlak van woordeboekstrukture.

Sedert die tagtigerjare van die vorige eeu het woordeboekstrukture, veral na aanleiding van die werk van die Duitse metaleksikograaf Herbert Ernst Wiegand, sterk op die voorgrond getree op die terrein van leksikografiese navorsing. Saakmakende publikasies is onder meer Wiegand (1989; 1989a; $1989 b ; 1996 ; 1998 ; 2003 ; 2008)$. In die onlangse metaleksikografiese navorsing is daar voortgegaan met werk ten opsigte van woordeboekstrukture vir gedrukte woordeboeke, vergelyk onder meer Wiegand en Beer (2013), Wiegand en Smit (2013), Wiegand, Beer en Gouws (2013), Wiegand, Feinauer en Gouws (2013) en Wiegand en Gouws (2013).

Naas die voortgesette gerigtheid op ' $n$ bespreking van strukture in gedrukte woordeboeke is daar eweneens aandag gegee aan van die moontlike aanpassings van woordeboekstrukture wat vir die benutting daarvan in die aanlyn woordeboeke geskik sal wees. Vergelyk in hierdie verband onder meer Klosa (2009), Müller-Spitzer (2013), Gouws (2014; 2014a; 2015,), Caruso (2015), Giacomini (2015), Klosa en Gouws (2015) en Müller-Spitzer en Wolfer (2015). In hierdie navorsing oor woordeboekstrukture vir aanlyn woordeboeke is dit veral aanpassings met betrekking tot die dataverspreidingstruktuur, raamstruktuur, skermskootstruktuur, makrostruktuur, mikrostruktuur, artikelstruktuur en adresseringstruktuur wat ter sprake gebring is. Gouws en Tarp (2016) dui 'n verskeidenheid vernuwende kenmerke in aanlyn woordeboeke aan, onder meer gesofistikeerde soekmetodes en toegangsroetes, gebruiker-gebaseerde datasifting, die gebruik van versteekte data, die gebruik van opskietvensters en nuwe tipes interne en eksterne skakels. Die voorkoms van hierdie kenmerke en 'n beskrywing wat 'n sistematiese benutting daarvan moontlik maak, vereis ook bepaalde aanpassings in sekere woordeboekstrukture.

Daar is ook reeds heelwat navorsing gedoen om die algemene leksikografie te verruim met ' $n$ bespreking van aspekte wat uitsluitlik op aanlyn woordeboeke gerig is. Vergelyk in hierdie verband die tematiese afdeling van die 2015uitgawe van die vaktydskrif Lexicographica wat gewy is aan strukture in aanlyn woordeboeke (Wiegand 2015).

Belangrik is dit om daarop te let dat hierdie aanpassings in die teorie onder meer dit ten doel het om uiteindelik een algemene en niemediumspesifieke leksikografieteorie te kan formuleer. 


\subsection{Uitbreiding van die teorie ter wille van verskillende leksikografiese werktuie}

Die oorgang na die digitale era het ook tot die benutting van verskillende tipes leksikografiese werktuie gelei. Anders as in die era van gedrukte woordeboeke waar die boek die werktuig was waarin die leksikografiese aanbod weergegee is, sluit die werktuie van die digitale era onder meer rekenaars, tablette en slimfone in. Toegang tot aanlyn woordeboeke kan met behulp van hierdie verskillende werktuie geskied. Waar die aard van die boek as werktuig selde 'n gesprekspunt was in die leksikografieteorie wat op gedrukte woordeboeke gerig was, speel die werktuig en die voordele en beperkinge van verskillende werktuie ' $n$ beduidende rol in die digitale era. Die benutting van ' $n$ bepaalde werktuig vir die daarstelling van 'n bepaalde woordeboek mag nie op 'n arbitrêre manier geskied nie. Die naslaan- en leksikografiese vaardighede van potensiële gebruikers moet ook deur leksikograwe in aanmerking geneem word wanneer daar besluit word oor die werktuig en die aard en omvang van die leksikografiese data wat daarin aangebied word. Verruiming in die bestek van die leksikografieteorie maak ook vir allerlei aspekte van leksikografiese werktuie se beperkings en voordele voorsiening. Dit vereis ' $n$ bykomende uitbreiding in die leksikografieteorie.

'n Aanlyn woordeboek wat saamgestel word met die oog op 'n slimfoon as werktuig se strukture sal verskil van dié van 'n woordeboek wat met behulp van 'n rekenaar geraadpleeg word. Die interne toegangstruktuur moet byvoorbeeld minder divers wees met 'n kleiner verskeidenheid tipografiese en nietipografiese struktuurmerkers in 'n verkleinde artikelstruktuur met minder soeksones en 'n beperkter aanduideraanbod. Op die interne soekroete moet daar wel voldoende leiding aan gebruikers gebied word om 'n suksesvolle inligtingsonttrekking per woordeboekraadpleging te verseker. Die keuse van 'n gepaste mikrostruktuurtipe is hier belangrik. Indien teksbegrip as kommunikatiewe funksie die enigste funksie van die betrokke woordeboek is, is 'n niegeïntegreerde of selfs ' $n$ rudimentêre mikrostruktuur voldoende. Waar teksproduksie die enigste funksie is, sal 'n geïntegreerde mikrostruktuur help om sukses te verseker. Indien die woordeboek bifunksioneel is met teksbegrip en teksproduksie as kommunikatiewe funksies, kan 'n semi-geïntegreerde mikrostruktuur, vergelyk Wiegand (1996), van waarde wees. Vir teksbegrip sal die geïntegreerde teksblok wat veral vertaalekwivalent- of betekenisparafrase-aanduiders en beperkte koteksaanduiders bevat die nodige leiding kan verskaf. Vir die teksproduksiefunksie van so 'n slimfoonwoordeboek sal koteksaanduiders soos voorbeeldmateriaal- en kollokasie-aanduiders in die niegeïntegreerde blok aangebied word.

In 'n woordeboek wat per rekenaar geraadpleeg word, sal die teksproduksiefunksie deur middel van voorbeeldmateriaalaanduiders in ' $n$ geïntegreerde mikrostruktuur uitgevoer kan word. ' $n$ Slimfoonwoordeboek moet die tipiese gebruiksituasie ter wille wees - daarom kan die artikelstruktuur aangepas word 
om 'n absolute verpligte mikrostruktuur, vergelyk Hausmann en Wiegand (1989: 346), oftewel 'n verpligte mikrostruktuur (Gouws 2003: 4) as verstekkomponent te hê. Daarbenewens kan daar 'n uitgebreide verpligte mikrostruktuur wees (vergelyk Gouws 2003: 4) wat op tweede en verdere skermskote aangebied kan word en wat bykomende data bevat.

Ruimte is en was dikwels 'n probleem in die samestelling van gedrukte woordeboeke en leksikograwe moes die inhoud van hulle woordeboeke dienooreenkomstig beplan. Waar die ruimtebeperking oorskry is deur die data-aanbod, moes die data-aanbod verminder word of daar moes voorsiening gemaak word vir twee- of meerdelige woordeboeke. In die beplanning van die dataverspreidingstruktuur, die lemmakeuse en die aard en omvang van die mikrostrukturele aanbod het die fisiese ruimtebeperkinge van 'n boek as leksikografiese werktuig 'n sekere rol gespeel.

Een van die voordele, hetsy 'n gewaande hetsy ' $n$ werklike voordeel, van aanlyn woordeboeke is die haas onbeperkte ruimte. Dit is so dat ruimtebeperking nie deurgaans dieselfde rol speel was wat in die beplanning en samestelling van gedrukte woordeboeke die geval is nie, maar onbeperkte ruimte geld nie altyd en oral in alle aanlyn woordeboeke nie. Lew (Om te verskyn) maak 'n onderskeid tussen die feitlik onbeperkte bergingsruimte in 'n aanlyn databasis en die beperkte aanbiedingsruimte, dit is die ruimte op 'n rekenaar- of ander skerm waar die data vertoon word. Waar ' $n$ woordeboek vir gebruik op 'n slimfoon beplan word, moet die leksikograwe die beperkinge van die werktuig met betrekking tot aanbiedingsruimte in gedagte hou. In die eerste fases van die ontwikkeling van Mobilex, 'n webgebaseerde selfoontoepassing wat gebruikers toegang gee tot 'n leksikografiese bewerking van 'n aantal terme uit enkele vakgebiede, is die data op 'n enkele skermskoot beperk tot 250 karakters, vergelyk Van der Merwe (2015). In die beplanning en samestelling van 'n woordeboek wat met behulp van 'n slimfoon geraadpleeg moet word, is dit belangrik dat daar gewaak word teen data-oorlading, vergelyk Gouws en Tarp (2016). In die leksikografieteorie moet 'n verskynsel soos data-oorlading ook verreken word nog ' $n$ vernuwing wat in die ontwikkeling van die leksikografie en die oorgang na 'n digitale era ter sake raak.

Die gebruik van 'n slimfoon of selfs 'n tablet of rekenaar waarvan die skerm ' $n$ beperkte aanbiedingsruimte het, impliseer nie noodwendig 'n beperkte leksikografiese bewerking nie. In die aanpassing van die teorie oor woordeboekstrukture het 'n fokus op die artikel- en skermskootstruktuur, vergelyk Gouws (2014), gewys op die waarde van 'n veelvlakkige artikelstruktuur waarvan al die data nie in 'n enkele skermskootstruktuur aangebied word nie. Vergelyk ook Du Plessis (2015). Die aard van die werktuig het dikwels 'n invloed op die gepaste strukture wat gebruik word.

\subsection{Die gebruiker}

Wiegand (1989c: 251) voer aan dat die leksikografie 'n praktyk is wat daarop 
gerig is om woordeboeke tot stand te bring sodat 'n verdere praktyk, te wete die kulturele praktyk van woordeboekgebruik moontlik gemaak kan word. Woordeboeke is praktiese gebruiksinstrumente en die suksesvolle gebruik van hierdie instrumente is 'n kerndoelstelling van die beplanning en samestelling van woordeboeke. Gevolglik is navorsing oor woordeboekgebruik 'n belangrike onderafdeling van die metaleksikografie, vergelyk onder meer Wiegand (1984: 15; 1998: 113). Vanuit hierdie navorsing word woordeboekmodelle geformuleer wat tot beter woordeboekgebruik kan lei.

In die ontwikkeling van die leksikografieteorie was daar algaande 'n sterker fokus op die gebruiker, met 'n toename in navorsing oor woordeboekgebruik en woordeboekgebruikers. Vergelyk onder meer Hartmann (1987), Atkins (1998), Tono (2001), Engelberg en Lemnitzer (2009), Svensén (2009), Welker (2013; 2013a). Gevolglik het Wiegand (1977: 59) se benoeming van die woordeboekgebruiker as die "bekende onbekende" aan geldigheid begin inboet. Die fokus op die gebruiker moet in die leksikografieteorie se aanpassing by e-woordeboeke gehandhaaf en selfs verder uitgebou word.

Soos in die geval van gedrukte woordeboeke staan die gebruiker sentraal in die beplanning en samestelling van aanlyn woordeboeke. Wiegand (1984: 15) het reeds woordeboekgebruik as 'n kernkomponent van die metaleksikografie geïdentifiseer en Hartmann (1989) het die beginsel van 'n gebruikersperspektief aan die orde gestel. Deur die daaropvolgende dekades was hierdie perspektief van kernwaarde in sowel die teoretiese as die praktiese leksikografie. In die metaleksikografie word die belang van die identifisering van 'n teikengebruikersgroep en die vasstelling van die leksikografiese behoeftes en naslaanvaardighede van daardie groep as voorvereistes gestel om die uiteindelike suksesvolle woordeboekgebruik te help verseker.

In die ontwikkeling van die leksikografieteorie het die erkenning aan die belang van die gebruikersperspektief tot bepaalde aanpassings gelei - weer eens in sowel die teorie as die praktyk. Hausmann (1989: 13) het reeds gebruikersvriendelikheid en woordeboekkultuur as leksikografiese terme gevestig. Gebruikersvriendelikheid in die leksikografie impliseer dat die leksikografie by die gemeenskap moet aanpas deur aan die gebruikers woordeboeke te lewer wat toeganklik is en waaraan inligting onttrek kan word ter bevrediging van hulle spesifieke leksikografiese behoeftes. Volgens Klotz en Herbst (2016: 33) is twee van die belangrikste faktore wat bydra tot gebruikersvriendelikheid in woordeboeke eerstens ' $n$ duidelike uitleg wat maklik interpreteerbaar is en wat duidelik tussen verskillende inligtingtipes onderskei en, tweedens, 'n duidelik intuïtiewe enkodering van inligting, veral die vermyding van obskure afkortings en kodes wat slegs verstaan kan word na die raadpleging van die woordeboek se voor- of agtertekste. Om 'n woordeboekkultuur gevestig te kry, moet die gemeenskap by die leksikografie aanpas deur vertroud te raak met onder meer verskillende woordeboeksoorte, die tipiese data wat in woordeboeke aangebied word, die waarde en beperkinge van verskillende woordeboeksoorte en met naslaanvaardighede om woordeboeke suksesvol te kan gebruik. 'n Woor- 
deboekkultuur sluit 'n samelewing se kennis van en vertroudheid met die leksikografie in asook die vermoë om woordeboeke op 'n kundige manier te kan gebruik. Vergelyk in hierdie verband ook Gouws en Prinsloo (2005: 12), Hartmann en James (1998) en Nkomo (2015). Waar 'n woordeboekkultuur in 'n bepaalde samelewing of taalgemeenskap geld, sal daar kundige woordeboekgebruikers wees, vergelyk Wiegand (1998: 506).

Die voortgesette ontwikkeling van die leksikografieteorie moet ook voorsiening maak vir en aanpas by die veranderde omgewing waarin woordeboeke gebruik word, spesifiek die digitale era, en die potensiële gebruikers van woordeboeke in hierdie era. Alle fasette van die leksikografieteorie, ook die gebruikersperspektief, moet telkens herbekyk en waar nodig aangepas word.

$\mathrm{Al}$ die veranderende invloede in die leksikografiese praktyk en teorie het 'n invloed op die woordeboekkultuur. Dit is daarom belangrik om vas te stel of die tradisionele bestek van die begrip woordeboekkultuur nog voldoende is en of daar aanpassings gemaak moet word in die interpretasie van hierdie begrip. Dit word vervolgens bespreek.

\section{3. 'n Omvattende woordeboekkultuur}

\section{1 'n Oorkoepelende term}

In verskeie publikasies, onder meer Gouws (2012; 2013; 2016; 2016a) is daar reeds gepleit vir 'n breër interpretasie van die begrip woordeboekkultuur. Gouws (2013; 2016: 108) voer aan dat die term woordeboekkultuur veral geïnterpreteer word met betrekking tot woordeboeke vir algemene taalgebruik. Dit is die woordeboeksoort waarmee die meeste woordeboekgebruikers bekend is. Die gewone lid van ' $n$ taalgemeenskap is veel minder bekend met ander woordeboeksoorte, onder meer die groot verskeidenheid vakwoordeboeke en hulle rol as naslaaninstrumente. Hierdie beperkte benadering tot woordeboekkultuur is te wagte as daar in ag geneem word dat woordeboeknavorsing, die metaleksikografie, dikwels 'n wetenskaplike aktiwiteit is wat slegs op algemene taalwoordeboeke gerig is. Vergelyk in hierdie verband Wiegand (1989: 257). Wiegand lewer 'n pleidooi vir die verbreding van kennis oor die leksikografie en die wetenskaplike studie daarvan, vergelyk Wiegand (1989: 258). 'n Vergelykbare verbreding kan ook ten opsigte van die begrip woordeboekkultuur en navorsing oor hierdie komponent van die leksikografie verlang word. 'n Omvattender siening van 'n woordeboekkultuur sal die samelewing se vertroudheid met woordeboeke verder as 'n kennis van slegs algemene taalwoordeboeke laat strek. Die aanpassing van die samelewing by die leksikografie moet gebruikers ook in aanraking bring met en hulle kennis verbreed van ander woordeboeksoorte, onder meer vakwoordeboeke.

'n Uitbreiding in die bestek van 'n woordeboekkultuur sluit ook ander fasette van die leksikografie in wat nie vroeër as deel van die woordeboekkultuur beskou is nie. Gouws (2016a) bespreek verskillende aspekte van woorde- 
boekkritiek en wys onder meer op die verantwoordelikheid van die metaleksikograaf teenoor die gemeenskap om deur middel van resensies die woordeboekgebruikende gemeenskap leiding te gee oor die gehalte en beskikbaarheid van woordeboeke. Woordeboekkritiek is 'n formele komponent van die metaleksikografie, vergelyk onder meer Wiegand (1984: 15; 1989: 262; 1998: 113). 'n Omvattender siening van woordeboekkultuur sluit ook die rol van woordeboekkritiek en 'n deeglike kennis van die rol en waarde van woordeboekkritiek by sowel die gebruiker as die leksikograaf in.

Die bestek van 'n omvattende woordeboekkultuur behoort nog verder te strek as byvoorbeeld 'n fokusverbreding om ook aan ander woordeboeksoorte en aan woordeboekkritiek aandag te gee. Wiegand (1998: 587) pleit ten gunste van die vestiging van die metaleksikografiese term gebruikersvriendelikheid maar laat hom nie in dieselfde mate oor die term woordeboekkultuur uit nie. Teenoor die term gebruikersoriendelikheid wat gereeld ook buite die leksikografie gebruik word, is die term woordeboekkultuur meer spesifiek leksikografies van aard. Vanuit hierdie terminologiese tweedeling kan die laasgenoemde term eerder as voorkeurterm in die leksikografie gebruik word, maar dan wel op so 'n manier dat dit as 'n oorkoepelende term dien vir dit wat tans as woordeboekkultuur en gebruikersvriendelikheid bekendstaan. Met die term omvattende woordeboekkultuur word daar voortaan in hierdie artikel na die tweerigtingverhouding tussen leksikografie en die gemeenskap verwys. Daar word gepleit vir 'n breë interpretasie van hierdie term wat veel meer insluit as wat tradisioneel as ter sake beskou is vir die suksesvolle verhouding tussen die gemeenskap en die leksikografie

Die belang van 'n omvattende woordeboekkultuur word so hoog geskat dat die invloed daarvan op 'n algemene leksikografieteorie erken behoort te word. Deur hierdie invloed word daar vanuit die metaleksikografie riglyne aan die leksikografiepraktyk gegee ter daarstelling van woordeboeke wat vir 'n veranderende gebruikersgroep se veranderende behoeftes in ' $n$ veranderende woordeboekgebruiksomgewing en vir ' $n$ veranderde medium en werktuigtipe voorsiening maak.

Naas 'n erkenning van die invloed van woordeboekkultuur op die leksikografieteorie kan 'n studie van woordeboekkultuur 'n formele onderafdeling van 'n algemene leksikografieteorie word. In die uiteensetting van die bestek van die metaleksikografie word daar onder die kategorie woordeboeknavorsing tans vir vier hoofkomponente voorsiening gemaak, naamlik woordeboekgebruiksnavorsing, kritiese woordeboeknavorsing, historiese woordeboeknavorsing en sistematiese woordeboeknavorsing, vergelyk Wiegand (1998: 118) en Schierholz (2016: 306). Om die leksikografie se verantwoordelikheid teenoor ' $n$ woordeboekkultuur deurgevoer te kry, moet woordeboekkultuur nie as 'n afsonderlike komponent van woordeboeknavorsing gesien word nie. Dit is veel eerder 'n afdeling van die leksikografieteorie wat in elkeen van hierdie hoofkomponente geïntegreer is omdat die navorsing wat ten opsigte van elkeen van hierdie komponente gedoen word dit onder meer ten doel het om die leksiko- 
grafie beter by die samelewing te laat aanpas. 'n Omvattende woordeboekkultuur is geïntegreer in 'n algemene leksikografieteorie.

\subsection{Indiwiduele en kollektiewe woordeboekkultuur}

Die bestaande terme gebruikersvriendelikheid en woordeboekkultuur word onderafdelings van 'n omvattende woordeboekkultuur. Uitbreiding van die bestek van die term omvattende woordeboekkultuur geld ten opsigte van sowel dit wat vroeër onder gebruikersvriendelikheid as onder woordeboekkultuur verstaan is. In die verhouding tussen leksikografie en samelewing moet die leksikografiepraktyk, met die leksikografieteorie as basis, produkte lewer wat die gebruiker meer ter wille is. Die keersy van die wisselwerkende verhouding is dat die vlak van woordeboekkultuur in 'n betrokke taalgemeenskap dit vir leksikograwe moontlik maak om meer gesofistikeerde woordeboeke te kan maak sonder vrees dat die potensiële teikengebruiker dit nie optimaal sal kan benut nie. Daar moet deur albei rolspelers in die aktiewe wisselwerkende verhouding tussen samelewing en leksikografie gepoog word om 'n omvattende woordeboekkultuur so wyd moontlik in die samelewing gevestig te kry.

Gouws (2013: 51) maak voorsiening vir die onderskeid tussen 'n indiwiduele en 'n samelewings- of kollektiewe woordeboekkultuur. Binne 'n samelewing of taalgemeenskap wat gekenmerk word deur die afwesigheid van 'n woordeboekkultuur kan daar indiwidue wees wat wel oor 'n woordeboekkultuur beskik. Dit sal 'n voorbeeld van indiwiduele woordeboekkultuur wees. Waar daar ' $n$ wydverspreide woordeboekkultuur in die samelewing geld, is dit 'n samelewings- of kollektiewe woordeboekkultuur. Die ideaal is dat 'n omvattende woordeboekkultuur ook 'n kollektiewe woordeboekkultuur is waaraan die grootste deel van 'n bepaalde samelewing of taalgemeenskap deel het. Een van die kenmerke van die digitale era is die grootskaalse toegang tot data deur 'n groot aantal gebruikers. 'n Kollektiewe woordeboekkultuur is ook hier nodig om die gebruikers van digitale woordeboeke en ander naslaanbronne vertroud te maak met die aard en omvang van die inligtingonttrekking aan aanlyn woordeboeke wat moontlik is. Hier gaan dit veral om die verskeidenheid datatipes en die gemak van toegang tot hierdie data wat vanuit 'n omvattende kollektiewe woordeboekkultuur bekendgemaak moet word.

\subsection{Aanpassings in die samelewing}

'n Omvattende woordeboekkultuur impliseer 'n tweerigtingwerking tussen leksikografie en samelewing. Aanpassings in die samelewing kan implikasies vir die leksikografie hê en aanpassings in die leksikografie kan implikasies vir die samelewing hê. Sulke aanpassings moet ook in die konseptualisering en formulering van die woordeboekkultuur weerspieël word. Van die veranderinge in die samelewing wat hier ' $n$ rol kan speel, is onder meer ' $n$ verskuiwing 
in die teikengebruikersgroepe van woordeboeke. Daar was byvoorbeeld in die voorafgaande dekades ' $n$ uitbreiding in die woordeboektipologie ten gunste van aanleerderwoordeboeke omdat taalaanleerders ' $n$ belangrike deel van die samelewing geword het en daarom as 'n teikengebruikersgroep van woordeboeke geïdentifiseer is. ' $n$ Woordeboekkultuur moes dus ook voorsiening maak vir aspekte wat deur so 'n verskuiwing van teikengebruikersgroepe meegebring is.

Die werktuie wat gebruik word in die digitale era het hulle eie voordele en beperkinge en dit verg ' $n$ eiesoortige tipe opleiding in woordeboekgebruiksvaardighede - ' $n$ faset wat ' $n$ komponent van ' $n$ omvattende woordeboekkultuur behoort te wees en wat tot sekere aanpassings moet lei.

Leksikograwe moet bewus wees van wie die teikengebruikers van hulle spesifieke woordeboeke is maar ook wat die wyer maatskaplike posisie en behoeftes van hierdie gebruikers is. Daar is ongetwyfeld buiteleksikografiese aspekte binne die samelewing wat 'n wesenlike invloed op die leksikografie kan uitoefen. ' $n$ Voorbeeld van so 'n buiteleksikografiese aspek is die tipiese gebruiksituasie van 'n beplande woordeboek. 'n Woordeboek vir gebruikers wat leerders in 'n omgewing is met onvoldoende fisiese geriewe sal heel moontlik anders lyk as 'n woordeboek van vergelykbare aard en omvang vir gebruikers in 'n gebruiksomgewing met optimale fisiese geriewe. Eersgenoemde woordeboek mag dalk primêr deur gebruikers wat in plakkerskampe woon, gebruik word. Die niebeskikbaarheid van voldoende elektriese lig mag meebring dat ter wille van suksesvolle woordeboekgebruik ' $n$ groter lettertipe in dié woordeboek gebruik word, vergeleke met die vergelykbare woordeboek wat saamgestel word vir leerders wat die woordeboek onder optimale gebruiksomstandighede gebruik. Hier lei gebruikersvriendelikheid nogmaals tot ' $n$ aanpassing van die leksikografie by die gemeenskap.

Die tipiese gebruiksituasie wat voorsien is vir die Ju/'hoan Tsumkwe Dialect/ Prentewoordeboek vir kinders/Children's picture dictionary (Jones et al. 2014) is nie 'n biblioteek, studeerkamer of goed toegeruste klaskamer nie, maar veel eerder 'n omgewing waar die woordeboek deur sy teikengebruikers, jong kinders, in 'n informeler situasie gebruik word. Die woordeboek se bladsye is van 'n dik en sterk glanspapier gemaak wat verhoed dat dit maklik skeur of vuil raak (Jones, persoonlike mededeling). Die leksikografie pas sy produk ook in terme van buiteleksikografiese aspekte aan by die gemeenskap wat die betrokke woordeboek gebruik. Voorskrifte in die leksikografieteorie moet soepel genoeg wees om vir sulke aanpassings voorsiening te maak.

'n Verandering in die kundigheidsvlak van potensiële teikengebruikers van woordeboeke is nog 'n buiteleksikografiese aspek wat 'n invloed op die leksikografiese teorievorming en praktyk kan hê en wat in 'n omvattende woordeboekkultuur verreken behoort te word. Naas die verrekening van verskuiwings in gebruikersgroepe lei die bewusmaking in 'n omvattende woordeboekkultuur van meer woordeboeksoorte as net algemene taalwoordeboeke daartoe dat daar ook aandag gegee moet word aan uiteenlopende gebruikers 
van dieselfde tipe woordeboek. In die vakleksikografie maak Bergenholtz en Tarp (1995: 19) voorsiening vir verskillende deelnemers aan vakgesprekke, te wete deskundiges, semideskundiges en leke. Hierdie gebruikers moet ook in ag geneem word by die vasstelling van 'n vakwoordeboek se teikengebruikergroep en die gevolglike datakeuse vir aanbieding in die woordeboek. In aansluiting by Bergenholtz en Tarp se driedeling stel Gouws (2016: 109) ' $n$ verdere gebruikerskategorie voor, naamlik die ingeligte leek. Dit gaan hier om leke ten opsigte van 'n bepaalde vakgebied wat deur gereelde blootstelling aan terme uit daardie vakgebied 'n sekere vertroudheid met die vakgebied verwerf. Waar vakterme in algemene aanlyn woordeboeke bewerk word, stel Gouws (2016: 113) voor dat naas die verstekbewerking vir die leek in die semantiese kommentaar van die woordeboekartikel daar ' $n$ bykomende teksblok in die artikelstruktuur opgeneem kan word waar 'n bewerking aangebied word wat toegevoegde waarde vir die ingeligte leek sal hê. Verdere ondersoek kan gedoen word om vas te stel of kundigheidsvlakke in ander opsigte ook tot 'n aanpassing in die verdeling van teikengebruikers lei. In die pedagogiese leksikografie word daar voorsiening gemaak vir verskillende taalaanleervlakke, naamlik ' $n$ beginnersvlak, intermediêre en gevorderde vlak. Vir die aanlyn leksikografie moet ' $n$ omvattende woordeboekkultuur daarvoor voorsiening maak dat gebruikers vertroud raak met doelgemaakte woordeboeke waar daar aan een databasis verskillende woordeboeke onttrek kan word - met die gebruiker wat sy/haar profiel moet opstel sodat ' $n$ woordeboek wat aan hulle behoeftes voldoen aan die databasis onttrek kan word. Vergelyk in hierdie verband Bergenholtz en Bergenholtz (2013). 'n Omvattende woordeboekkultuur is ook op gebruikersvriendelikheid gerig wat impliseer dat die leksikografie aanpassings moet maak om produkte te lewer wat ten beste in al hierdie verskillende gebruikersgroepe se leksikografiese behoeftes kan voorsien. In hierdie verband is dit ook noodsaaklik dat gebruikers vertroud moet wees en vertroud gemaak moet word met die elektroniese toestel waarop die woordeboeke verskyn. Dit is 'n buiteleksikografiese aspek wat aandag verdien in die uitbreiding van 'n omvattende woordeboekkultuur. ${ }^{1}$

Nog 'n buiteleksikografiese aspek wat ingrypende leksikografiese implikasies kan hê, is die omstandighede van potensiële woordeboekgebruikers in die digitale era met verwysing na hulle vertroudheid met tegnologiese vordering en hulle houding teenoor gedrukte bronne, veral naslaanbronne. 'n Groot persentasie van die lede van die samelewing wat ' $n$ behoefte aan betroubare naslaanbronne het, behoort tot die jonger geslag. Dit is mense wat in die digitale era gebore is en daarin opgroei. Om te probeer verseker dat daar 'n voortgesette behoefte aan die gebruik van woordeboeke sal wees, moet die woordeboekkultuur ook deur die naslaanbehoeftes en naslaanvoorkeure van hierdie geslag potensiële gebruikers beïnvloed word. Die digitale era is die era van Generasie Z en die leksikografie moet op hulle behoeftes reageer. 'n Omvattende woordeboekkultuur moet ook buiteleksikografiese aanpassings in die samelewing in ag neem en die leksikografie moet daarby aanpas. 


\section{Generasie Z}

Generasie Z, ook bekend as Gen Z, sluit diegene in wat na 1990 gebore is, dit is die kinders van Generasie X (gebore 1965-1976) en die kinders of kleinkinders van die Baby Boomers (gebore 1946-64) en soms selfs reeds die kinders van Generasie $Y$ (gebore 1977-1998), vergelyk http://de.wikipedia.org/wiki/Generation_Y. Alhoewel baie Gen Z-lede nog op skool is, behoort hulle binne 'n dekade die grootste deel van die werkkrag uit te maak, aldus Asthana (2008). Dit is 'n geslag wat met die internet opgegroei het en hulle nie 'n lewe daarsonder kan voorstel nie. Volgens die urbandictionary:

This generation is very networked with social networks and many means of communication and means of entertainment at their finger tips such as Cell Phones, iPod, Facebook, YouTube and IM. Digital networking and sharing is common and many have not known a time without the internet ... (http://www.urbandictionary.com)

Hierdie netbewoners ("net citizens" of "netizens") stel ander verwagtinge aan naslaanbronne. Volgens Generation Z: Born in the digital age (2011) glo hulle dat alles moontlik is met behulp van tegnologie en lei hulle 'n lewe:

that seems a million miles removed from the hopes, dreams and morals of previous generations ... They want everything, everywhere and immediately. They surf on two screens simultaneously. They don't mind paying through the nose for the latest smart phone but turn up their nose at paying for a film or a song when you can get that for free online. ... Even as young as they are, they have already seen so many technologies become obsolete. For this reason, they have become the ultimate "self-educators", learning how to use new stuff via self-help videos on YouTube.

Leksikograwe wat leksikografiese produkte vir die onmiddellike toekoms beplan, moet die tipiese kenmerke van Gen $\mathrm{Z}$ in gedagte hou want dit gaan ' $\mathrm{n}$ invloed op hulle naslaanbehoeftes, woordeboekgebruik en woordeboekgebruiksvaardighede hê. Dit vereis ingrypende aanpassings in die leksikografieteorie en die leksikografiepraktyk en 'n verdere verbreding van 'n omvattende woordeboekkultuur. Gedrukte bronne is nie Gen Z se voorkeurleesstof nie en hierdie gebrek aan belangstelling in boeke, hulle voorkeur vir gratis aanlyn produkte en hulle vermeende vermoë om hulleself met behulp van die internet op te voed, moet leksikograwe daarvan oortuig dat hulle met 'n deel van die samelewing te doen het onder wie tradisionele woordeboeke min of geen invloed het nie, vergelyk Gouws (2017) en Gouws en Tarp (2016).

Parker (2013) beweer dat indien Gen Z digitale integreerders is

then we can't teach them in analogue, where teachers do the teaching, spoonfeeding them knowledge. Those days are gone.

In 'n omvattende woordeboekkultuur moet daar voorsiening gemaak word vir hierdie potensiële teikengebruikers van nuwe leksikografiese produkte. Woor- 
deboekdidaktiek moet ook hierby aangepas word. Die gesprek oor leksikografiese hulpmiddels moet nie tot aanlyn woordeboeke beperk word nie, maar ander inligtingsinstrumente wat deur Gen Z gebruik word, moet ook in gedagte gehou word en leksikografiese produkte moet waar moontlik daarby geïntegreer word. Gen Z is ook die selfoongenerasie omdat selfone ' $n$ onafskeidbare en onvervreembare deel van die meeste lede van hierdie generasie is. O'Farrell (2011) wys op die hoë persentasie van die tienerbevolking wat selfone besit. Drie dinge wat selfone aan hierdie gebruikers gee, is toeganklikheid, gewildheid en verbindbaarheid.

Die gemak en onmiddellike bevrediging van kommunikatiewe behoeftes wat selfone meebring, is heel belangrik vir leksikografiese produkte. Daarom moet leksikograwe probeer om leksikografiese produkte te integreer in slimfone om waarde toe te voeg tot hierdie veelsydige instrumente en daardeur ' $n$ beter kans te bewerk om woordeboekgebruik onder Gen Z-lede te vestig. Dit sluit aan by die gedagtes van Finch (2015):

It's critical that we recognize Gen Z's differences and meet them where they are, rather than where we want them to be.

Dit is ook in die leksikografie ter sake en leksikograwe moet woordeboeke dienooreenkomstig beplan maar ook die woordeboekkultuur dienooreenkomstig aanpas en woordeboekdidaktiek, spesifiek die aanleer van woordeboekgebruiksvaardighede, dienooreenkomstig aanpas. Vergelyk in hierdie verband ook Gouws (2017). Nkomo (2015: 74) sê:

No form of culture can thrive without being inculcated or nurtured by means of education, be it formal or informal. The same applies to dictionary culture ...

Hier moet woordeboekdidaktiek 'n aktiewe rol speel om die sukses van 'n omvattende woordeboekkultuur te help verseker.

\section{Woordeboekdidaktiek}

Dit is 'n gevestigde siening in die leksikografie dat die opleiding van woordeboekgebruikers ' $n$ noodsaaklikheid is. Binne die tradisionele siening van ' $n$ woordeboekkultuur, dit is die aanpassing van die gemeenskap by die leksikografie, kan woordeboekopleiding as 'n ononderhandelbare komponent beskou word. Whitcut (1986) wys reeds op die belang van die opleiding van woordeboekgebruikers. In 'n omvattende woordeboekkultuur moet woordeboekdidaktiek ook as ononderhandelbare komponent gesien word, maar die opleiding moet op sowel woordeboekgebruikers as leksikograwe gerig wees. Lew (2013: 16) wys op twee belangrike aspekte wat nodig is vir suksesvolle woordeboekgebruik. Dit is hoë gehalte, gebruikersvriendelike woordeboeke en woordeboekgebruikers wat weet wat hulle doen. Hierdie twee aspekte weerspieël die kern van die tradisionele tweedeling van gebruikersvriendelikheid en 
woordeboekkultuur en dus ook die kern van die tweerigtingverhouding wat ' $n$ omvattende woordeboekkultuur kenmerk. Om leksikograwe daartoe in staat te stel om hoë gehalte gebruikersvriendelike woordeboeke saam te stel en om gebruikers te hê wat weet wat hulle doen, is opleiding, spesifiek woordeboekdidaktiek, noodsaaklik.

Die behoefte aan woordeboekdidaktiek word gereeld in metaleksikografiese publikasies bespreek. Vergelyk in hierdie verband onder meer Béjoint (1989), Lew en Galas (2008), Engelberg en Lemnitzer (2009), Schierholz (2016) en vir aanlyn woordeboeke Klein (2008). Domínguez Vázquez en Sanmarco Bande (2017) word volledig gewy aan die tema leksikografie en didaktiek. Die behoefte aan formele opleiding vir leksikograwe het gelei tot die instelling van graadkursusse in teoretiese leksikografie, onder meer in Suid-Afrika aan die Universiteit van Stellenbosch en die toonaangewende MA-program EMLex, dit is die interuniversitêre, internasionale European Master in Lexicography, vergelyk http://www.emlex. phil.uni-erlangen.de/.

Volgens Klein (2007: 423) is dit vir 'n suksesvolle woordeboekkultuur nodig dat daar voortdurend samewerking tussen leksikograwe en onderwysers moet wees. Die onderwysers is, aldus Klein, 'n belangrike faktor in die ontwikkeling van 'n woordeboekkultuur. Vir die digitale era moet woordeboekdidaktiek gerig wees op vaardighede in die gebruik van aanlyn woordeboeke maar daar moet ook die nodige fokus op die tipiese gebruikers van hierdie aanlyn woordeboeke wees. Die behoeftes en vaardighede van lede van Gen Z stel nuwe uitdagings aan die leksikografieteorie. In 'n samelewing met ' $n$ aktiewe omvattende woordeboekkultuur wat gekenmerk word deur die aanpassing van die gemeenskap by die leksikografie en van die leksikografie by die gemeenskap moet die digitale era 'n invloed hê op die aanpassings wat deur albei groepe rolspelers in die woordeboekkultuur gemaak word - ook ten opsigte van woordeboekdidaktiek. Leksikograwe moet kreatief dink oor vernuwende maniere waarop woordeboekgebruik en woordeboekgebruiksvaardighede onderrig moet word. Vergelyk in hierdie verband onder meer DringóHorváth (2014) en Tiberius en Müller-Spitzer (2015). In hierdie beplanning moet woordeboeke nie in isolasie gesien word nie maar as deel van ' $n$ veel wyer reeks digitale naslaanbronne. Woordeboekvaardighede moet ook vaardighede meebring om ander aanlyn naslaanbronne te raadpleeg. Mettertyd kan ' $n$ omvattende woordeboekkultuur uitgebrei word tot 'n omvattende naslaankultuur.

\section{Ten slotte}

Die sukses van woordeboeke as praktiese gebruiksinstrumente is daarvan afhanklik dat die kundige teikengebruikers weet wanneer om watter woordeboek te kies, weet watter data in watter woordeboek aangebied behoort te word en daartoe in staat is om toegang te kry tot die data waaraan die tersaaklike inligting onttrek moet word. Wanneer ' $n$ woordeboekraadpleging afgesluit 
word met die verkryging van inligting wat 'n oplossing bied vir die probleem wat die woordeboekraadpleging gemotiveer het, is daar sprake van sukses. Suksesvolle woordeboekgebruik en die maak van woordeboeke wat aan die geïdentifiseerde teikengebruikersgroep se leksikografiese behoeftes voldoen, word bevoordeel deur die bestaan van 'n omvattende woordeboekkultuur met 'n tweerigtingwerking tussen die leksikografie en die samelewing. Met die oog op die digitale era waar lede van Gen $\mathrm{Z}$ oorreed moet word om woordeboeke as naslaanbronne te gebruik en waar aanlyn woordeboeke ook op die behoeftes van Gen Z gerig is, is die vestiging van 'n omvattende woordeboekkultuur maar ook voortgesette metaleksikografiese navorsing om die gehalte van die woordeboekkultuur te verbeter en uit te brei dringend noodsaaklik.

\section{Nota}

1. My dank aan 'n anonieme keurder wat my aandag op hierdie aspek gevestig het.

\section{Erkenning}

This research is supported in part by the National Research Foundation of South Africa (grant specific unique reference number (UID 85434). The Grantholder acknowledges that opinions, findings and conclusions or recommendations expressed in any publication generated by the NRF supported research are that of the author, and that the NRF accepts no liability whatsoever in this regard.

\section{Bibliografie}

\subsection{Woordeboeke}

Hartmann, Reinhard R.K. en Gregory James. 1998. Dictionary of Lexicography. Londen/New York: Routledge.

Johnson, S. 1755. A Dictionary of the English Language. Londen: J. \& P. Knapton/T. \& T. Longman et al. Jones, Kerry L. et al. (Reds.). 2014. Ju/'hoan Tsumkwe Dialect/Prentewoordeboek vir kinders/Children's Picture Dictionary. Pietermaritzburg: University of KwaZulu-Natal Press.

urbandictionary $=\mathrm{http}: / / \mathrm{www} \cdot$ urbandictionary.com

\subsection{Ander bronne}

Asthana, Anushka. 2008. They Don't Live for Work ... They Work to Live. http://www.theguardian. com/money/2008/may/25/workandcareers.worklifebalance.

Atkins, Beryl T.S. (Red.). 1998. Using Dictionaries. Studies of Dictionary Use by Language Learners and Translators. Tübingen: Max Niemeyer. 
Béjoint, Henry. 1989. The Teaching of Dictionary Use: Present State and Future Tasks. Hausmann, Franz-J. et al. (Reds.). 1989-1991: 208-215.

Bergenholtz, Henning en Sven Tarp (Reds.). 1995. Manual of Specialised Lexicography. Amsterdam/ Philadelphia: John Benjamins.

Bergenholtz, Inger en Henning Bergenholtz. 2013. One Database, Four Monofunctional Dictionaries. Hermes 50: 119-125.

Caruso, Valeria. 2015. Explorations on Data Condensation and Data Distribution in the Microstructures of e-Dictionaries. Lexicographica 31: 38-66.

Domínguez Vázquez, Maria. J. en M.T. Sanmarco Bande (Reds.). 2017. Lexicografía y Didáctica. Frankfurt: Peter Lang. (Om te verskyn.)

Dringó-Horváth; Ida. 2014. Wörterbuchdidaktik für digitale Wörterbücher. http://www.daf-online.hu/ docs/DringoHorvath_2014_Woerterbuchdidaktik_218-228.pdf.

Du Plessis, André. 2015. 'n Funksionele analise van die e-WAT: 'n Grondslag vir die verbetering van internet- en selfoonwoordeboeke. Ongepubliseerde M.A.-tesis. Universiteit van Stellenbosch.

Engelberg, Stefan en Lothar Lemnitzer. 2009: Lexikographie und Wörterbuchbenutzung. Tübingen: Stauffenburg.

Finch, Jeremy. 2015. What Is Generation Z, And What Does It Want? http://www.fastcoexist.com/ 3045317/what-is-generation-z-and-what-does-it-want.

Generation Z: Born in the Digital Age. 2011. http://english.astroawani.com/lifestyle/generation-zborn-digital-age-53754.

Giacomini, Laura. 2015. Macrostructural Properties and Access Structures of LSP e-Dictionaries for Translation: The Technical Domain. Lexicographica 31: 90-117.

Gouws, Rufus H. 2003. Aspekte van mikrostrukturele verskeidenheid en inkonsekwentheid in woordeboeke. Lexikos 13: 92-110

Gouws, Rufus H. 2005. Meilensteine auf dem historischen Weg der Metalexikographie. Lexicographica 21: 158-178.

Gouws, Rufus H. 2012: Towards a System of Integrated Dictionary Use. Karpova, Olga en Faina Kartashkova (Reds.). 2012. Multi-disciplinary Lexicography: Traditions and Challenges of the XXI-st Century: 134-144. Cambridge: Cambridge Scholars Publishing.

Gouws, Rufus H. 2013. Establishing and Developing a Dictionary Culture for Specialised Lexicography. Jesenšek, Vida (Red.). 2013. Specialised Lexicography: 51-62. Berlyn/New York: De Gruyter.

Gouws, Rufus H. 2014. Article Structures: Moving from Printed to e-Dictionaries. Lexikos 24: 155-177.

Gouws, Rufus H. 2014a. Makrostruktuuraanpassings vanaf gedrukte na e-woordeboeke. Tydskrif vir Geesteswetenskappe 54(3): 481-504.

Gouws, Rufus H. 2015. Expanding the Notion of Addressing Relations. Lexicography: 1(2): 159-184.

Gouws, Rufus H. 2016. Increasing the Scope of the Treatment of Specialised Language Terms in General Dictionaries. Schierholz, Stefan et al. (Reds.). 2016: 101-118.

Gouws, Rufus H. 2016a. Dictionary Criticism and Dictionary Critics. Bielińska, Monika and Stefan J. Schierholz (Reds.). 2016. Wörterbuchkritik. Berlyn: De Gruyter. (Om te verskyn.)

Gouws, Rufus H. 2017. La sociedad digital y los diccionarios. Domínguez Vázquez, Maria. J. en Sanmarco M.T. Bande (Reds.) 2017. Lexicografía y Didáctica. Frankfurt: Peter Lang. (Om te verskyn.)

Gouws, Rufus H., Ulrich Heid, Wolfgang Schweickard en Herbert Ernst Wiegand (Reds.). 2013. Dictionaries. An International Encyclopedia of Lexicography. Supplementary Volume: Recent Devel- 
opments with Focus on Electronic and Computational Lexicography. Berlyn/New York: Walter de Gruyter.

Gouws, Rufus H. en Danie J. Prinsloo. 2005. Principles and Practice of South African Lexicography. Stellenbosch: SUN PReSS.

Gouws, Rufus H., Wolfgang Schweickard en Herbert Ernst Wiegand. 2013. Lexicography through the Ages: From the Early Beginnings to the Electronic Age. Gouws, Rufus H. et al. (Reds.). 2013: 1-24.

Gouws, Rufus H. en Sven Tarp. 2016. Information Overload and Data Overload in Lexicography. International Journal of Lexicography 29. (Om te verskyn.)

Hartmann, Reinhard R.K. 1987. Four Perspectives on Dictionary Use: A Critical Review of Research Methods. Cowie, Anthony P. (Red.). 1987. The Dictionary and the Language Learner: 11-28. Tübingen: Niemeyer.

Hartmann, Reinhard R.K. 1989. Sociology of the Dictionary User: Hypotheses and Empirical Studies. Hausmann, Franz J. et al (Reds.). 1989: 102-111.

Hausmann, Franz J. 1989. Die gesellschaftlichen Aufgaben der Lexikographie in Geschichte und Gegenwart. Hausmann, Franz J. et al. (Reds.). 1989-1991: 1-19.

Hausmann, Franz J. et al. (Reds.). 1989-1991. Wörterbücher. Ein internationales Handbuch zur Lexikographie/Dictionaries. An International Encyclopedia of Lexicography/Dictionnaires. Encyclopédie internationale de lexicographie. Berlyn: De Gruyter.

Hausmann, Franz J. en Herbert Ernst Wiegand. 1989. Component Parts and Structures of General Monolingual Dictionaries: A Survey. Hausmann, Franz J. et al. (Reds.). 1989-1991: 328-360.

Johnson, S. 1747. The Plan of a Dictionary of the English Language. Faksimilee-uitgawe 1970. Menston: The Scolar Press.

Klein, Juliane. 2007. Implementing a Dictionary Culture in South Africa: An Attempt at a General Framework for the African Languages. Lexikos 17: 416-423.

Klein, Juliane. 2008. Teaching Dictionary-using Skills for Online Dictionaries: An Attempt at a Theoretical Framework for South Africa. Bernal, Elisenda en Janet DeCesaris (Reds.). 2008. Proceedings of the XIII EURALEX International Congress, Barcelona, 15-19 July 2008: 1265-1271. Sèrie Activitats 20. Barcelona: Universitat Pompeu Fabra, Institut Universitari de Lingüística Aplicada.

Klosa, Annette. 2009. Außentexte in elektronischen Wörterbüchern. Beijk, Egbert et al. (Reds.). 2009. Fons Verborum: Feestbundel Fons Moerdijk: 49-60. Amsterdam: Gopher BV.

Klosa, Annette en Rufus H. Gouws. 2015. Outer Features in e-Dictionaries. Lexicographica 31: 142172.

Klotz, Michael en Thomas Herbst. 2016. English Dictionaries. A Linguistic Introduction. Berlyn: Erich Schmidt Verlag.

Lew, Robert. 2013. Online Dictionary Skills. Kosem, Iztok et al. (Reds.). 2013. Electronic Lexicography in the 21st Century: Thinking outside the Paper: 16-31. Ljubljana/Tallinn: Trojina, Institute for Applied Slovene Studies/Eesti Keele Instituut.

Lew, Robert. Om te verskyn. Space Restrictions in Paper and Electronic Dictionaries and their Implications for the Design of Production Dictionaries. Bański, Piotr en Beata Wójtowicz (Reds.). Om te verskyn. Issues in Modern Lexicography. München: Lincom Europa.

Lew, Robert en Katarzyna Galas. 2008. Can Dictionary Skills Be Taught? The Effectiveness of Lexicographic Training for Primary-School-Level Polish Learners of English. Bernal, Elisenda en Janet DeCesaris (Reds.). 2008. Proceedings of the XIII EURALEX International Congress, Barcelona, 
15-19 July 2008: 1273-1285. Barcelona: Universitat Pompeu Fabra.

McArthur, Tom. 1986. Worlds of Reference. Lexicography, Learning and Language from the Clay Tablets to the Computer. Cambridge: Cambridge University Press.

Müller-Spitzer, Carolin. 2013. Textual Structures in Electronic Dictionaries. Gouws, Rufus H. et al. (Reds.). 2013: 367-381.

Müller-Spitzer, Carolin en Sascha Wolfer. 2015. Vernetzungsstrukturen digitaler Wörterbücher. Neue Ansätze zur Analyse. Lexicographica 31: 173-199.

Nkomo, Dion. 2015. Developing a Dictionary Culture through Integrated Dictionary Pedagogy in the Outer Texts of South African School Dictionaries: The Case of Oxford Bilingual School Dictionary: IsiXhosa and English. Lexicography 2(1): 71-99.

O'Farrell, Nicholas. 2011. http://www.ning.com/blog/2011/07/generation-mobile1.html.

Parker, Phil. 2013. http://www.sec-ed.co.uk/blog/how-generation-z-is-different.

Schierholz, Stefan. 2016. Einige kurze Überlegungen zur Metalexikographie in der Lehre. Schierholz, Stefan, et al. (Reds.). 2016: 295-308.

Schierholz, Stefan, et al. (Reds.). 2016. Wörterbuchforschung und Lexikographie. Berlyn: De Gruyter.

Svensén, Bo. 2009. A Handbook of Lexicography: The Theory and Practice of Dictionary-making. Cambridge: Cambridge University Press.

Tarp, Sven. 2008. Lexicography in the Borderland between Knowledge and Non-knowledge. General Lexicographical Theory with Particular Focus on Learner's Lexicography. Tübingen: Max Niemeyer.

Tiberius, Carole en Carolin Müller-Spitzer. 2015. Research into Dictionary Use. Wörterbuchbenutzungsforschung. 5. Arbeitsbericht des wissenschaftlichen Netzwerks "Internetlexikografie“. Mannheim: Institut für Deutsche Sprache.

Tono, Yukio. 2001. Research on Dictionary Use in the Context of Foreign Language Learning. Focus on Reading Comprehension. Tübingen: Max Niemeyer.

Van der Merwe, Michele. 2015. Perceptions of the MAAL Generation in Higher Education on the Use of LSP Dictionaries on Mobile Phones. Paper presented at the StelleLex-Colloquium, Stellenbosch, March 2015.

Welker, Andreas. 2013. Empirical Research into Dictionary Use since 1990. Gouws, Rufus H. et al. (Reds.). 2013: 531-540.

Welker, Andreas. 2013a. Methods in the Research of Dictionary Use. Gouws, Rufus H. et al. (Reds.). 2013: 540-547.

Whitcut, Janet. 1986. The Training of Dictionary Users.Ilson, Robert (Red.). 1986. Lexicography: An Emerging International Profession: 111-122. Manchester: Manchester University Press.

Wiegand, Herbert Ernst. 1977. Nachdenken über Wörterbücher: Aktuelle Probleme. Drosdowski, Günther, Helmut Henne en Herbert E. Wiegand (Reds.). 1977. Nachdenken über Wörterbücher: 51-102. Mannheim/Wenen/Zürich: Bibliographisches Institut.

Wiegand, Herbert Ernst. 1984. On the Structure and Contents of a General Theory of Lexicography. Hartmann, Reinhard R.K. (Red.). 1984. LEX'eter '83 Proceedings. Papers from the International Conference on Lexicography at Exeter, 9-12 September 1983: 13-30. Tübingen: Max Niemeyer.

Wiegand, Herbert Ernst.1989. Aspekte der Makrostruktur im allgemeinen einsprachigen Wörterbuch: Alphabetische Anordnungsformen und ihre Probleme. Hausmann, Franz J. et al. (Reds.). 1989-1991: 371-409.

Wiegand, Herbert Ernst. 1989a. Der Begriff der Mikrostruktur: Geschichte, Probleme, Perspektiven. Hausmann, Franz J. et al. (Reds). 1989-1991: 409-462. 
Wiegand, Herbert Ernst. 1989b. Arten von Mikrostrukturen im allgemeinen einsprachigen Wörterbuch. Hausmann, Franz J. et al. (Reds). 1989-1991: 462-501.

Wiegand, Herbert Ernst. 1989c. Der gegenwärtige Status der Lexikographie. Hausmann, Franz J. et al. (Reds.). 1989-1991: 246-280.

Wiegand, Herbert Ernst. 1996. Das Konzept der semiintegrierten Mikrostrukturen. Ein Beitrag zur Theorie zweisprachiger Printwörterbücher. Wiegand, Herbert Ernst (Red.). 1996. Wörterbücher in der Diskussion II. Vorträge aus dem Heidelberger lexikographischen Kolloquium: 1-82. Tübingen: Max Niemeyer.

Wiegand, Herbert Ernst. 1998. Wörterbuchforschung. Untersuchungen zur Wörterbuchbenutzung, zur Theorie, Geschichte, Kritik und Automatisierung der Lexikographie. 1. Teilband. Mit 159 Illustrationen im Text. Berlyn/New York: Walter de Gruyter.

Wiegand, Herbert Ernst. 2003. Überlegungen zur Typologie von Wörterbuchartikeln in Printwörterbüchern. Ein Beitrag zur Theorie der Wörterbuchform. Lexicographica 19: 169-313.

Wiegand, Herbert Ernst. 2008. Zugriffsstrukturen in Printwörterbüchern. Ein zusammenfassender Beitrag zu einem zentralen Ausschnitt einer Theorie der Wörterbuchform. Lexicographica 24: 209-315.

Wiegand, Herbert Ernst (Red.). 2015. Lexicographica 31. Berlyn: De Gruyter.

Wiegand, Herbert Ernst en Sandra Beer. 2013. Access Structures in Printed Dictionaries. Gouws, Rufus H. et al. (Reds.). 2013:110-149.

Wiegand, Herbert Ernst, Sandra Beer en Rufus H. Gouws. 2013. Textual Structures in Printed Dictionaries: An Overview. Gouws, Rufus H. et al. (Reds.). 2013: 31-73.

Wiegand, Herbert Ernst, Ilse Feinauer en Rufus H. Gouws. 2013. Types of Dictionary Articles in Printed Dictionaries. Gouws, Rufus H. et al. (Reds.). 2013:314-366.

Wiegand, Herbert Ernst en Rufus H. Gouws. 2013. Macrostructures in Printed Dictionaries. Gouws, Rufus H. et al. (Reds.). 2013: 73-110.

Wiegand, Herbert Ernst en Maria Smit. 2013. Microstructures in Printed Dictionaries. Gouws, Rufus H. et al. (Reds.). 2013: 149-214.

\subsection{Webblaaie}

http://de.wikipedia.org/wiki/Generation_Y.

http://www.emlex.phil.uni-erlangen.de/ 